most famous "ophthalmic surgeon" of Germany last summer, and for an enormous astigmatism (of which the surgeon was utterly incurious) he ordered massage of the eyes by the patient. For blepharitis, due to refractive error, anothes famous man told another patient to squeeze out the secretion of the Meibomian glands with her fingers. A great French oculist ordered simple isometropic spherical lenses for astigmatic anisometropia, and expressed indignant surprise at the idea that he, the oculist, should have kept any record of the Ienses he had ordered. I could enumerate many such laughable instances. But such things are common enough in America aIso, and to gibe at the refraction of the fetus in utero does not make them less common.

It is true that extremes are dangerous and that the middleof-the-road is usually the safest and truest. Not always, however! A compromise, if for the sake of compromise, may be a worse error than either extreme. The time is not far past when one who should have proposed to cure strabismus (and surely heterophoria!) by any other method than operation would have been looked on as crazy.

George M. Gould, M.D.

\section{Midshipman Aikin and Vivisection.}

Philladelphia, Dec. 5, 1902.

\section{Hon. JacoB H. Gallinger,}

Chairman of the Senate Committee on the District of Columbia, Washington, D. C.

My Dear Sir: As you have repeatedly introduced bills into the Senate for the purpose nominally of regulating experiments on animals in the District of Columbia, which bills, however, if they had become laws, would in fact have prohibited many, if not all of them, I deem it my duty to call your attention to the case of Midshipman Aikin of the United States Naval Academy, who was recently injured in a football game. My reason for doing so is to show you by a single conerete example that knowledge gained by animal experimentation is an immense boon to humanity and that, therefore, such experiments should be heartily encouraged.

The facts of Mr. Aikin's case are as follows: When $I$ first saw him, three days after the accident, I found that he had been unconscious for a half hour after the accident and ever since then had complained bitterly of headache, which he located always in the forehead. Mentally he was very dull, though not comatose. His pulse was slowed down to 52 instead of being 72 , the normal. Soon after the accident he began to develop convulsions, first in the right leg, afterward in the right arm also, the right arm being finally the chief seat of the convulsions. When they were very severe they involved the left side also. The face was never involved. In six hours and a half after I first saw him he had 24 of these attacks, all limited to the right arm. They were not attended by any loss of consciousness. They exhausted him very greatly, especially when they were excessively severe. Several times it was necessary to give him chloroform.

There was no fracture of the skull. The only physical evidence of any injury was a very slight bruise at the outer end of the left eyebrow.

Had I seen this case before 1885 I would have been unable to explain why the spasms were chiefly manifested in the right arm, and from the evidence of the slow pulse, the headache, the stupor, the bruise in the left temple, etc., I would have been justified in inferring that probably the front part of the brain was injured at the site of the bruise. Had I opened his skull at that point I would have found a perfectly normal brain and have missed the clot. The young man, therefore, would have died, whether his skull had been opened or not.

In 1902 observe the difference. As a result of the knowl. edge derived from experiments on animals which have Iocated precisely the center for motion of the right arm on the left side of the brain near the top and a little in front of a vertical line drawn through the ear, and disregarding entirely the site of the headache and the bruise, I reached the conclusion that there had been a rupture of a blood vessel within the head, which had poured out a quantity of blood, and that the situation of the clot should correspond to the "arm center." The location of this arm center was far away (about three inches) from the location of the bruise, and its position was fixed absolutely as a result of experiments on animals, con firmed later by many operations on human beings and also by postmortems.

As soon as the skull was opened at this point the clot was found, its thickest point being exactly over the arm center and nine tablespoonfuls of blood were removed, with the result that the patient's life has been saved. The blood had first been poured out over the "leg center," which is located a little higher up than that for the arm. This explained the early spasms in the right leg. The elot did not extend, how. ever, further down than the arm center. This explained why the face was never convulsed, for the "face center" lies just below that for the arm.

I think if you were to ask the parents of this young man how many animals they would be willing to have sacrificed in order that their son might have his life saved, there would be no doubt of the answer. Indeed, had it been your own son, I can not doubt the answer. But this is only one of hundreds of cases in which a similar exact localization has been made by many surgeons, both in Europe and America. Yet, by a curious coincidence, in the very same issue of a Baltimore newspaper containing a reporter's account of the successful operation on Midshipman Aikin there is a letter signed by an active antivivisectionist agitator, which, among other misstatements and misrepresentations usually found in such publications, asserts that "brain surgery is disregarded."

If the laws which you and your friends advocate were in force, the conditions for scientific investigation in medicine in this country would be quite as deplorable as those in England. For example, when Lord Lister, who has revolutionized modern surgery, largely as a result of such experiments, wished to discover possibly some still better way of operating by further experiments, he was obliged to go to Toulouse to carry them out, as the vexatious restrictions of the law in Eng land practically made it impossible for him to continue there these pre-eminently humane experiments.

Again, when Sir T. Lauder Brunton in London started a series of experiments on animals to discover an antidote for the cobra and other snake poisons of India, where every year 20,000 human lives are sacrificed by snake bites, these beneficent researches were stopped by the stringent British laws to protect animals. Meanwhile half a million of human beings have hopelessly perished.

Who, I may ask, is the more humane; he who, doubtless with the best and sincerest motives of love for dumb beasts, would prohibit experiments on animals and thereby prevent the acquisition of such knowledge and so compel surgeons to stand with folded arms and see innumerable lives thus needlessly sacrificed; or he who, by properly instituted experiments, would discover such new truths and apply them to the service of humanity?

The antivivisectionists have frequently denied that surgeons have learned anything from such experiments. I presume that I may be considered a competent witness as to the source, at least, of my own knowledge, and I state with the greatest positiveness that without the knowledge derived from experiments on animals which have demonstrated the facts of cerebral localization, I should never have been able to locate the clot in Mr. Aikin's head and to remove it, nor would I have been able in the last fifteen years to locate numerous tumors and other brain troubles and relieve many of them. What is true of myself is equally true of other surgeons.

In view, therefore, of the evident and positive benefit of such experiments, I trust that you will be willing to desist from further efforts at such repressive and, as I regard it, most inhumane and cruel legislation.

As this matter is of vital importance to the well-being of the entire community, I shall take the liberty of giving this letter to the press as soon as you have received it. Yours very respectively, W. W. KEEN, Professor of Surgery, Jefferson Medical College. 